\title{
Clonal analysis of isolated intestinal metaplastic glands of stomach using X linked polymorphism
}

\author{
S Nomura, M Kaminishi, K Sugiyama, T Oohara, H Esumi
}

\begin{abstract}
Background-Monoclonal precancerous cells undergo successive biochemical and genetic changes during the multistep process of carcinogenesis in the gastrointestinal tract. Despite a high association with intestinal-type stomach cancer (differentiated adenocarcinoma of the stomach), the role of intestinal metaplasia is unclear in stomach carcinogenesis.

Aims-To study the clonality of intestinal metaplasia.

Methods-The clonality of 86 single intestinal metaplastic glands isolated by EDTA treatment from gastrectomy specimens from patients with cancer were investigated. The methylation sensitive restriction enzyme HpaII and polymerase chain reaction (PCR) were used to detect a polymorphic human androgen receptor gene locus linked to an inactive $X$ chromosome. Results-Forty one (48\%) intestinal metaplastic glands were heterotypic (mixed cells of different allelic methylation) and $45(52 \%)$ were homotypic (cell population of the same allelic methylation), while almost all the single pyloric glands were homotypic. Eleven of 13 intestinal metaplastic mucosae that were $6 \mathrm{~mm}$ in diameter contained glands that had originated from different cells. There were no strong relationships between clonal type and location or histological type of intestinal metaplasia.
\end{abstract}

Conclusion-Intestinal metaplasia in general is not a lesion that arises or proceeds monoclonally.

(Gut 1998;42:663-668)

Keywords: clonality; intestinal metaplasia; methylation; $\mathrm{X}$ chromosome inactivation; stomach; gastric cancer

\section{Dr H Esumi, Investigative}

Treatment Division, National

Cancer Center Research

Institute East, 6-5-1

Kashiwanoha, Kashiwa-shi,

Chiba 277, Japan.

Metaplasia is defined as the conversion of one differentiated cell type into another, which occurs in postnatal life. ${ }^{12}$ Intestinal metaplasia in the stomach is one of the commonest types

Accepted for publication 26 November 1997

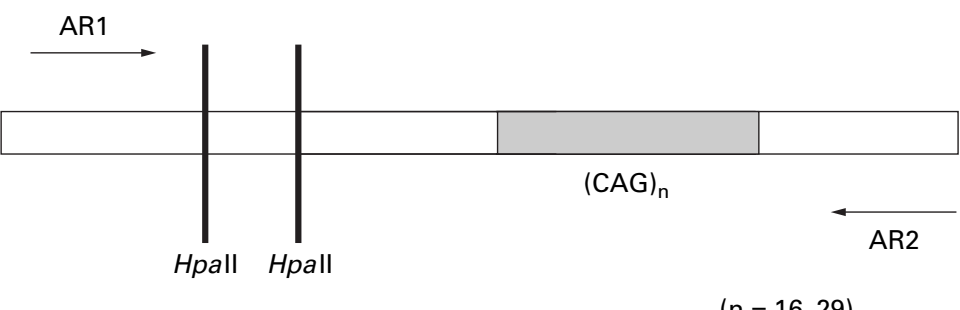

Figure 1 Schematic representation of HUMARA gene. There is one polymorphic CAG repeat and two HpaII sites, which are methylation sensitive. These sites are completely methylated on inactive $X$ alleles and unmethylated on active $X$ alleles. The repetition number of the CAG is from 16 to 29 in Asian people. found in humans. ${ }^{2}$ The intestinal metaplastic gland is reported to initially arise from the proliferating zone at the neck of a normal gland. ${ }^{3}$ Once cells of the intestinal type arise, they replace normal glandular cell types throughout the gland. ${ }^{3}$ Macroscopically, intestinal metaplastic lesions most commonly arise at the antrum, which is normally covered by pyloric glands, and the intermediate zone, which is normally covered by a mixture of fundic and pyloric glands, and the lesion expands with age. ${ }^{34}$

Intestinal-type gastric cancer has been reported to be surrounded by an intestinal metaplastic area, which may have one of three explanations. ${ }^{56}$ (1) The intestinal metaplasia is a direct precancerous lesion. (2) The intestinal metaplasia causes an appropriate milieu for carcinogenesis, perhaps by raising the $\mathrm{pH}$ of the gastric juice, thus improving growing conditions for bacteria that produce mutagens. (3) The intestinal metaplasia is just a paraneoplastic lesion resulting from the same mutagenic stimuli that gave rise to the cancer. ${ }^{5}$

Intestinal metaplastic tissue can be classifed histologically into two types: complete (type I) and incomplete (types IIa and IIb).$^{7-12}$ The complete type is associated with the intestinal marker enzymes sucrose $\alpha$-D-glucohydrolase, $\alpha, \alpha$-trehalase, aminopeptidase, and alkaline phosphatase. ${ }^{13}$ Tissue of this type contains goblet cells and Paneth's cells but not sulphomucin. ${ }^{13}$ The incomplete type is associated with sucrose $\alpha$-D-glucohydrolase, aminopeptidase, goblet cells, and sulphomucin, but not with $\alpha, \alpha$-trehalase, alkaline phosphatase, or Paneth's cells. ${ }^{13}$ Type IIb intestinal metaplastic tissue secretes sulphomucins, and is particularly known to accompany the intestinal type of gastric cancer..$^{7-13}$

A "neoplasm" can be defined as a clone of cells distinguished from other tissues by autonomous growth and somatic mutations. ${ }^{14}$ Some cancers have been reported to be monoclonal, based on analysis of $\mathrm{X}$ chromosome inactivation, and this is compatible with somatic mutation theories of carcinogenesis. ${ }^{14-17}$ Some lesions that are called precancerous have also been reported to be monoclonal. ${ }^{18}{ }^{19}$ Fearon et $a l^{20}$ have reported that all colonic cancers and colonic adenomas are monoclonal using $\mathrm{X}$ chromosome methylation. However, Novelli et $a l^{21}$ have reported that the earliest adenomas in familial adenomatous polyposis coli are polyclonal. If the cancer arises from multiple step accumulation of genetic changes, there should be a point at which it starts to expand monoclonally. ${ }^{14}$ If intestinal metaplasia is a direct precancerous lesion, it is possibile that it has already expanded monoclonally. 
In recent years, clonal analysis has become possible by utilising $\mathrm{X}$ chromosome methylation. ${ }^{22}$ Certain $\mathrm{CpG}$ sites of one of the two $\mathrm{X}$ chromosome alleles of a female cell are reported to be methylated in the early stages of development, and this methylation is fixed within the cell's somatic heredity. ${ }^{23}{ }^{24}$ In a monoclonal cell population that has proliferated from one cell, all the methylated $\mathrm{X}$ alleles are of the

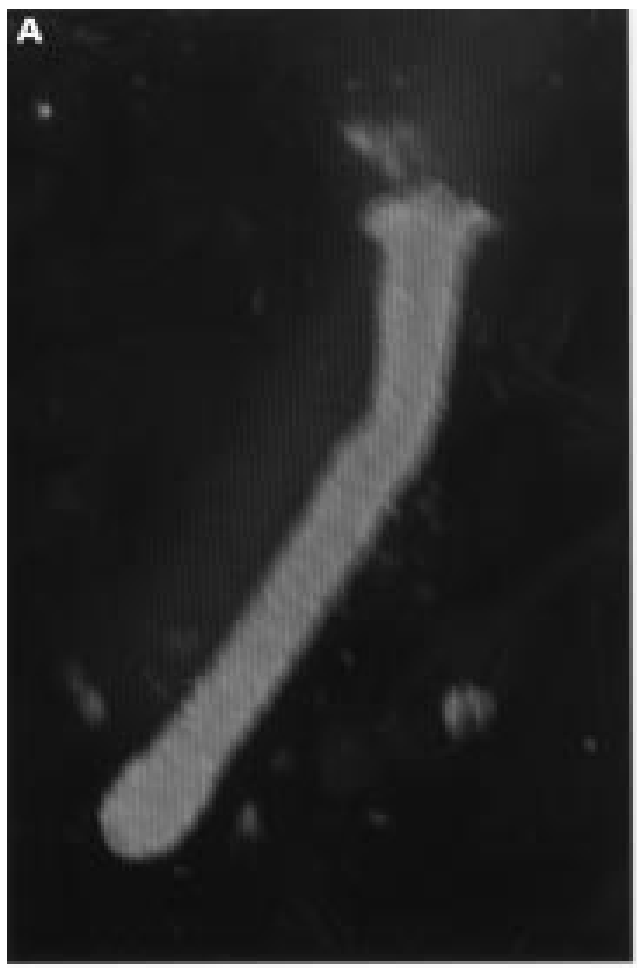

c

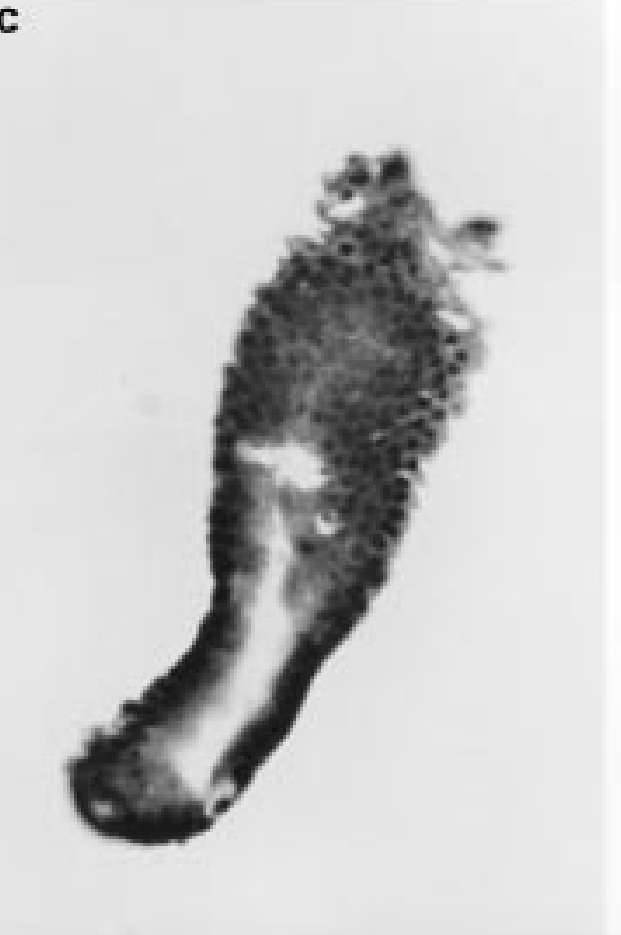

same origin, paternal or maternal. ${ }^{22-24}$ If the two $\mathrm{X}$ chromosomes are distinguishable, a cell population can be said to be polyclonal or possibly monoclonal. ${ }^{22}$ We have used the term "homotypic" for a cell population that is methylated on the same allele, and "heterotypic" for a mixed cell population that is methylated on different alleles in this report, because some cell populations, which have arisen from plural cells

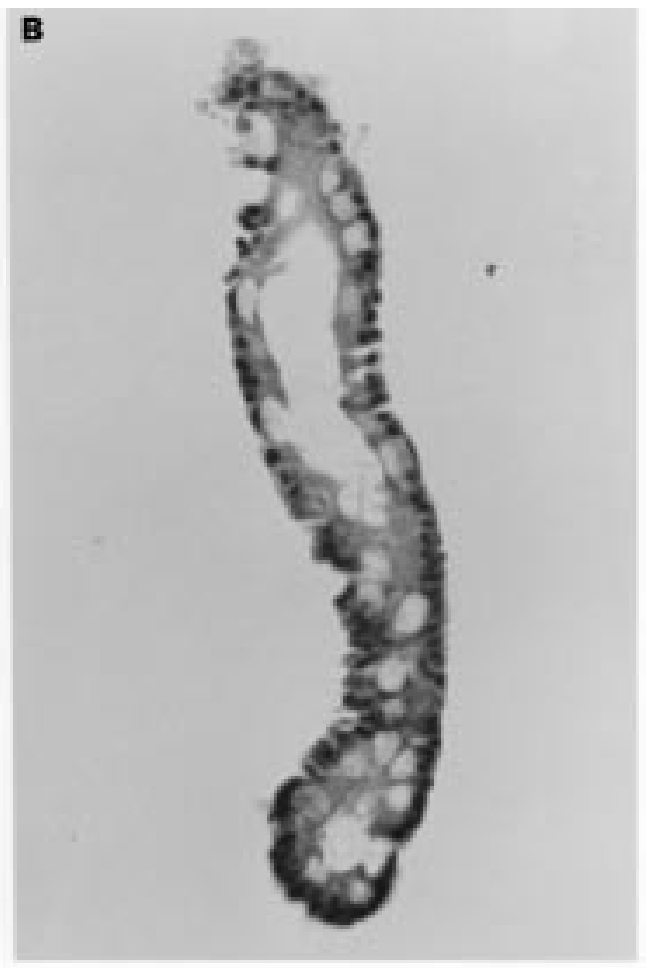

D

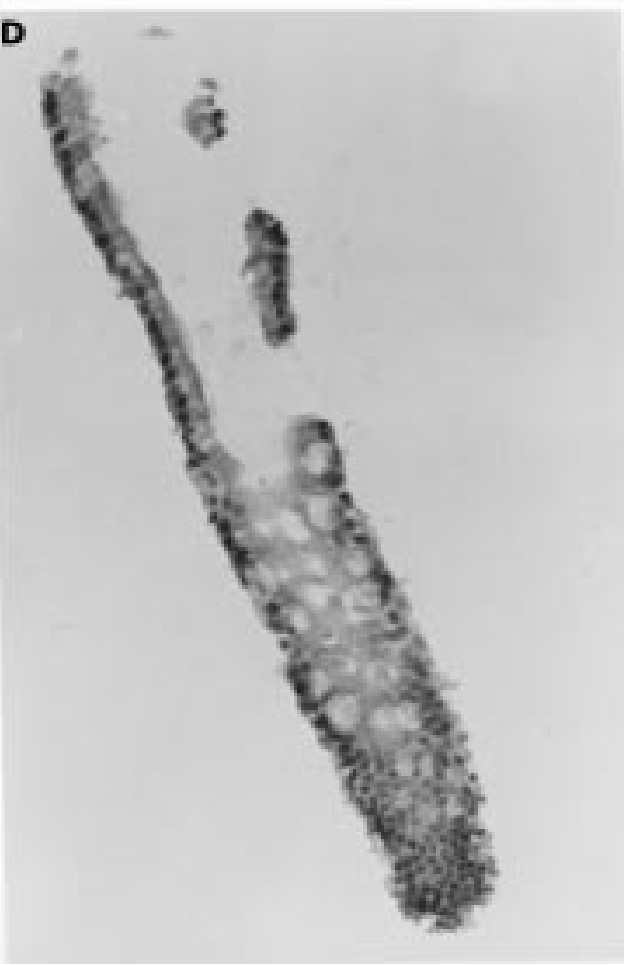

Figure 2 Single intestinal metaplastic gland. (A) A feature under a stereomicroscope; original magnification $\times 70$. (B) $-(D)$ Sectioned and haematoxylin and eosin stained features of the gland under a microscope; original magnification $\times$ 100. These three glands are heterotypic, although there were no interstitial tissues. 
Table 1 Details of clonality of intestinal metaplastic glands obtained from each small punch out

\begin{tabular}{llllll}
\hline Type and location & $\begin{array}{l}\text { Punched } \\
\text { out no }\end{array}$ & $\begin{array}{l}\text { Homotypic } \\
\text { (longer peak) }\end{array}$ & $\begin{array}{l}\text { Homotypic } \\
\text { (shorter peak) }\end{array}$ & Heterotypic & Total \\
\hline Complete; antrum & C2-1 & 6 & 1 & 2 & 9 \\
& C3-1 & 2 & 2 & 0 & 4 \\
Complete; intermediate & C3-2 & 0 & 6 & 3 & 9 \\
Zone & C2-2 & 1 & 0 & 6 & 7 \\
& C3-3 & 5 & 3 & 0 & 8 \\
Incomplete; antrum & C3-4 & 0 & 1 & 5 & 6 \\
& C1-1 & 0 & 2 & 5 & 7 \\
& C2-3 & 0 & 1 & 0 & 1 \\
Incomplete; & C3-5 & 1 & 0 & 6 & 6 \\
intermediate zone & C2-5 & 2 & 2 & 7 & 10 \\
& C2-6 & 0 & 1 & 5 & 8 \\
& C3-6 & 0 & 2 & 0 & 2 \\
\hline
\end{tabular}

C2-1, case number 2; punched out number 1 .

that are methylated on the same allele by chance, are homotypic although they are polyclonal.

We analysed the clonality of single intestinal metaplastic glands on the basis of a polymorphism of the $\mathrm{X}$ linked human androgen receptor gene (HUMARA) and $\mathrm{X}$ chromosome methylation. ${ }^{25} 26$ The single glands were analysed separately on the basis of histological type (whether they were complete or incomplete) and location (antrum or intermediate zone) in the stomach to determine whether a given area of intestinal metaplasia is a clonal expansion of a metaplastic gland.

\section{Methods}

SPECIMENS

Three gastrectomy specimens were obtained from three female patients with gastric cancer who had been operated on at the National Cancer Center Hospital, East, Japan, in April 1996. All three cases (C1, C2, C3) were heterozygous for the $H U M A R A$ gene.

The specimens were examined by the Tes-Tape method with trehalose and sucrose; lesions of intestinal metaplasia were detected with sucrose and separated into complete and incomplete types using trehalose. ${ }^{27}$ Intestinal metaplastic mucosa was punched out with a 6 $\mathrm{mm}$ diameter dispopunch (Maruho Co., Osaka, Japan) from the large intestinal metaplastic lesion in the antrum or the intermediate zone. The punching out was performed as far away as possible from the cancer. One half of each punched out tissue sample was examined histologically and the other half used for gland isolation.

\section{GLAND ISOLATION}

This process was performed as reported previously. ${ }^{28}$ Briefly, the tissue sample was incubated for 30 minutes at $37^{\circ} \mathrm{C}$ in $5 \mathrm{ml} \mathrm{Hanks} \mathrm{bal-}$ anced salt solution containing $30 \mathrm{mM}$ EDTA, and the isolated glands were picked up by needles under stereomicroscopic observation. ${ }^{29}$ All the glands were embedded frozen into OCT compound Tissue-Tek (Miles Inc., Elkhart, IN, USA) and each isolated gland was sectioned longitudinally into $5 \mu \mathrm{m}$ slices until the goblet cells could be seen. The slices were stained with haematoxylin and eosin, and we confirmed that the glands were intestinal metaplastic by micro- scopic verification of the presence of goblet cells. The remaining glands in the OCT compound were thawed and picked up under a stereomicroscope.

\section{CLONAL STUDY}

Figure 1 shows a schematic representation of the HUMARA gene. ${ }^{25}$ It has a polymorphic CAG repeat, which is repeated between 16 and 29 times in Asian people. ${ }^{30}$ More than $90 \%$ of Asian women are heterozygous for this repeat. There are two methylation sensitive $H p a$ II sites near this repeat, and these sites are reported to be completely methylated on the inactivated X allele and unmethylated on the active allele. ${ }^{25} 26$ Polymerase chain reaction (PCR) performed on the locus containing both these HpaII sites and the CAG repeat after digestion with HpaII only amplifies the methylated alleles. If the cell population is monoclonal, a single PCR product is obtained, because all the methylated alleles have the same number of CAG repeats. If it is polyclonal, two types of product, originating from the maternal and paternal alleles, are obtained. Clonal analysis was essentially based on the methods reported previously. ${ }^{25}{ }^{26}{ }^{28}$ Briefly, $3 \mu \mathrm{l}(0.6-1.2 \mathrm{ng})$ DNA was mixed with $1 \mu \mathrm{l}$ enzyme solution containing $1.25 \mathrm{U} R s a \mathrm{I}$ (with and without $1 \mathrm{U}$ of HpaII) and digested for 12 hours at $37^{\circ} \mathrm{C}$. RsaI, which digests DNA other than the template DNA, enables accurate PCR on smaller amounts of DNA. The amount of DNA extracted from the rest of a single gland was estimated at 3-10 ng. Amplification of a portion of the HUMARA gene in exon 1 was performed using primers AR1 and AR2, essentially as described by Mutter et al. ${ }^{26} \mathrm{AR} 1$ was labelled at the 5 ' end with indodicarbocyanine (Cy5). PCR was performed as reported previously. ${ }^{28}$ External controls containing 0.6 ng and 3.0 ng mixed DNA obtained from the blood of a healthy woman and a healthy man were used in all series to confirm that only the methylated alleles were amplified. DNA samples were diluted to between 0.6 and 3.0 ng per tube. The PCR products were analysed using an automated sequencer (ALFred; Pharmacia) and quantified using the Fragment Manager software package (Pharmacia).

\section{Results}

Thirteen punched out lesions were obtained from three specimens. All the lesions, which were analysed histologically, contained intestinal metaplastic tissue, and were typed by the Tes-Tape method. ${ }^{1327}$ Figure 2 shows a representative isolated single intestinal metaplastic gland along with the sectioned view. Almost all the isolated intestinal metaplastic glands were simple straight glands, whereas about half of the fundic and pyloric glands isolated had branching. ${ }^{28}$ Between one and ten glands containing goblet cells were obtained from each punched out lesion (table 1). There was no contamination with interstitial tissues in any of the sectioned views of the isolated glands (fig 2), and Paneth cells could not be detected.

Figure 3 shows representative results of the clonal analyses. When DNA was not digested 


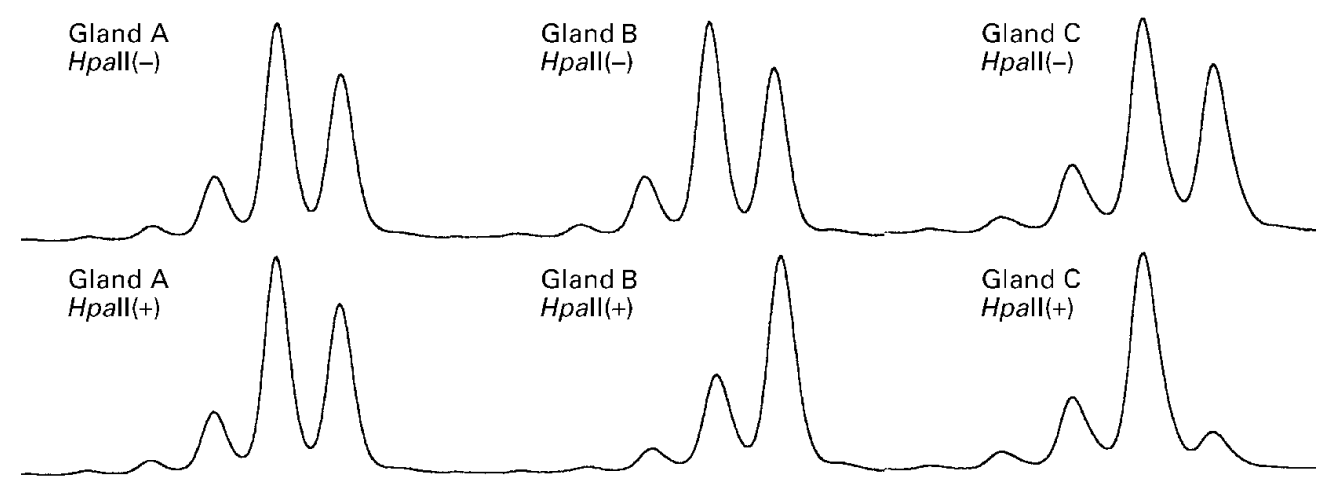

Figure 3 Representative clonal analysis. All the samples were analysed in pairs consisting of those not digested and those digested with HpaII. In the ALFred pattern, the PCR product of higher molecular mass is on the right, with the lower molecular mass product on the left. The peaks on the right are products of longer repeats of HUMARA, and those on the left are products of shorter repeats. Gland $A$, heterotypic. The results after digestion with HpaII are the same as those with no digestion. Gland B, homotypic of longer allelic methylation. Gland C, homotypic of shorter allelic methylation. HpaII(-), not digested with HpaII; HpaII(+), digested with HpaII.

with HpaII, two peaks were observed in heterozygous patients. When the samples were heterotypic (mixed cells with different allelic methylation), two peaks were retained even after HpaII digestion. When the samples were homotypic (cell populations with the same allelic methylation), one of the peaks decreased significantly in the HpaII digested sample. From conditional studies, more than $20 \%$ contribution of the minor type of DNA can be detected as heterotypic by this method of analysis (data not shown). All 86 DNA samples were analysed twice, and all the outcomes were in accord.

Table 1 summarises the results of the clonal analysis of the single intestinal metaplastic glands. From the specimen of case 1 (C1), only incomplete type intestinal metaplastic lesions in the antrum were obtained. Four types of lesion-that is, complete in the antrum, complete in the intermediate zone, incomplete in the antrum, and incomplete in the intermediate zone-were obtained from cases 2 and 3 . Two lesions only contained one type of homotypic gland; the incomplete type C2-3 (case 2, lesion 3 ) in the antrum and the incomplete type C2-6 in the intermediate zone. Only one or two glands were obtained from these lesions. Most of the punched out lesions (11/13) contained heterotypic or both types of homotypic gland.

Table 2 summarises the total number of clonal types. In the complete type in the antrum, 17 glands were homotypic and five were heterotypic. In the complete type in the intermediate zone, 10 were homotypic and 11 were heterotypic. In the incomplete type of the antrum, six were homotypic and 18 were heterotypic. In the incomplete type in the intermediate zone, 12 were homotypic and seven were heterotypic. Of a total of 86 glands, $45(52 \%)$ were homotypic, and 41 (48\%) were heterotypic. Although there were some deviations, there was no correlation between the

Table 2 Summary of clonal analysis of single intestinal metaplastic glands

\begin{tabular}{|c|c|c|c|c|c|}
\hline & \multicolumn{2}{|c|}{ Complete type } & \multicolumn{2}{|c|}{ Incomplete type } & \multirow[b]{2}{*}{ Total } \\
\hline & Antrum & Intermediate zone & Antrum & Intermediate zone & \\
\hline Homotypic & 17 & 10 & 6 & 12 & $45(52 \%)$ \\
\hline Heterotypic & 5 & 11 & 18 & 7 & $41(48 \%)$ \\
\hline
\end{tabular}

clonal type and the histological type or the location of the lesion. One gland out of eight from one punched out lesion of the complete type in the intermediate zone $(\mathrm{C} 2-2)$ showed a loss of heterozygosity. This gland showed one peak in the ALFred pattern even before digestion with HpaII, and was excluded from the results of the clonal analysis.

We obtained three intestinal metaplastic glands showing replication errors (RERs) from the punched out lesion C1-2, which was an incomplete-type intestinal metaplastic lesion from the antrum (fig 4). When PCR was performed without prior HpaII digestion, all the glands of this case ( $\mathrm{C} 1$ ) showed two peaks as seen for $\mathrm{C} 1-1-1$ (case 1 , lesion 1 , gland 1) in fig 4. However, three glands (C1-2-1, 2, 3) from one punched out lesion showed one additional peak of a longer repeat, indicating an RER of the HUMARA gene. Although all three of these glands showed the same type of RER, clonal analysis indicated that each of the three had a different methylation pattern after digestion with HpaII (fig 4). The examination of these three glands was performed in triplicate with the same results. These three glands were also excluded from the clonal analysis. They had no histological differences from the other intestinal metaplastic glands.

\section{Discussion}

In clonal analysis it is important to rule out contamination with interstitial tissue. ${ }^{20}$ In this analysis, we used the gland isolation technique reported by Cheng et al. ${ }^{29}$ The isolated glands were confirmed to contain no interstitial tissue by being sliced and stained with haematoxylin and eosin. Even though contamination could not be completely ruled out, it was found to be less than $20 \%$ for all cells. We used this technique on colonic crypts, and found them all to be homotypic, as reported by Ponder et $a l .{ }^{31}$ Some clonal analyses have used microdissection in cases where there was no alternative approach possible. ${ }^{32}$ The gland isolation technique that we employed is both useful and reliable because DNA can be obtained from unfixed cells; however, one disadvantage is that 


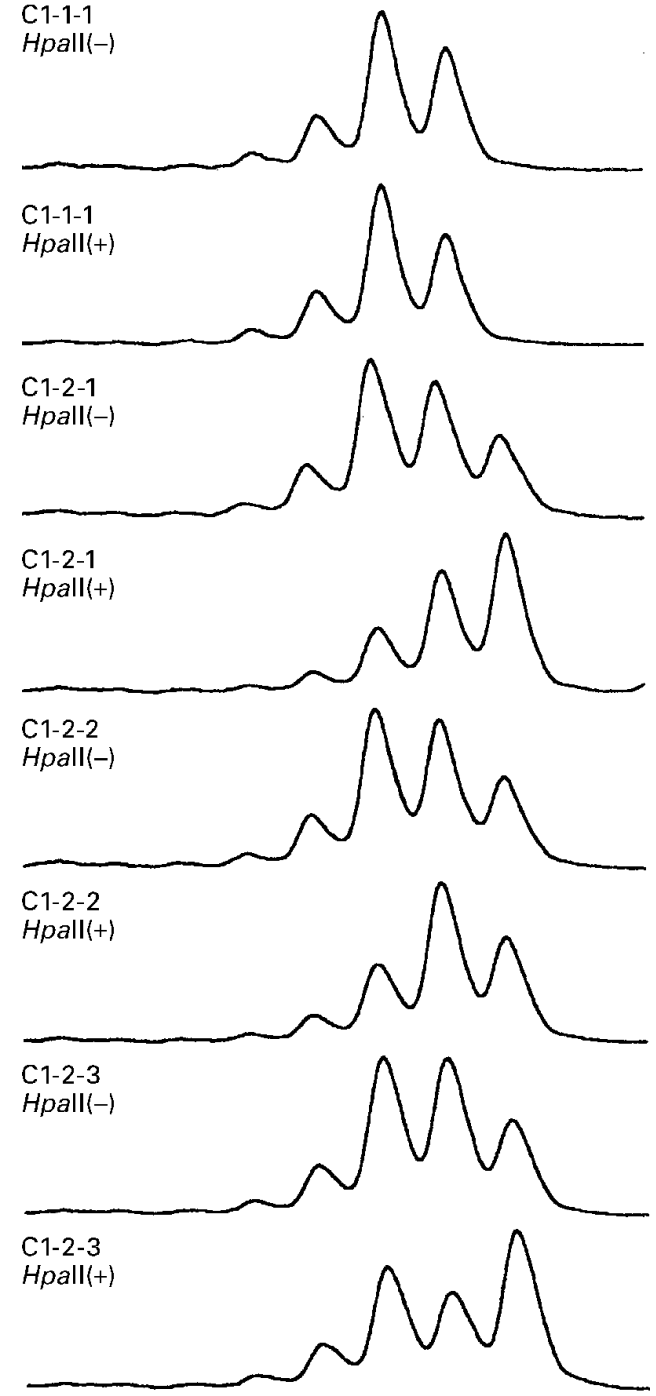

Figure 4 Results for three glands that showed replication errors (RERs). Gland C1-1-1 (case 1, lesion 1, gland 1) is a control gland from the same case, which is heterotypic and does not show RERs. The profiles for the three glands (C1-2-1, C1-2-2, C1-2-3) have one extra small peak on the right when they are not digested with HpaII. The profiles all differ after digestion with HpaII.

it is impossible to reconstruct the positional relationships of neighbouring glands.

The intestinal metaplastic glands are composed of several types of epithelial cell, but about half of the glands were found to be homotypic. ${ }^{5}$ Can this be attributed to the sensitivity of the method we used? We recently analysed the clonality of gastric mucosa using tissue sections from transgenic mice carrying $\mathrm{X}$ linked $l a c Z$ genes, and the homotypic glands were composed entirely of cells of the same clonal type, although the gastric glands contained several types of cell (data not shown).

At least $50 \%$ of the intestinal metaplastic tissue in the present study was polyclonal in origin, even when separated into the smallest lesion, a gland. This finding was quite unexpected and is probably concordant with the recent suggestion by Bjerknes et $a l^{33}$ that some crypts in dysplastic adenoma of patients with familial polyposis are polyclonal. In addition, most of the small punch out lesions of intestinal metaplastic tissue were a mixture of glands originating from different cells. Therefore the present data indicate that intestinal metaplasia is a polyclonal lesion. Slack et $a l^{12}$ proposed that one tissue can be replaced by another, either by a switch of developmental commitment or by colonisation with cells of different origin, and that only the former is true metaplasia. The present data indicate that intestinal metaplasia is true metaplasia, because each intestinal gland is known to be monoclonal with respect to $\mathrm{X}$ chromosome methylation, and intestinal metaplasia cannot be explained by the expansion of intestinal mucosa into the stomach from the duodenum. ${ }^{31}$ Intestinal metaplasia is thought to arise from a switch of developmental commitment, but the switch has to occur in plural neighbouring stem cells to become polyclonal.

Most of the punched out lesions (11/13) contained glands originating from different cells. The remaining two lesions gave only one or two glands. From these findings, the intestinal metaplastic areas may not expand monoclonally to larger than $6 \mathrm{~mm}$ in diameter. In this respect, intestinal metaplasia is not a direct precancerous lesion proceeding monoclonally. Ochiai et $a l^{34}$ has found some clonal expansion of intestinal metaplasia with a p53 mutation, indicating monoclonality. Therefore some of the intestinal metaplasia could be a monoclonal expansion, but our present data indicate that intestinal metaplasia is in general not monoclonal. However, in intestinal metaplasia, cells may be in a metastable phase and are highly susceptible to the subsequent monoclonal multistep carcinogenesis. ${ }^{14}$

Intestinal metaplasia type IIb, in which sulphomucin is secreted, is reported to have a strong correlation with intestinal-type gastric cancer. ${ }^{7-12}$ In this report, we used a gland isolation technique involving EDTA treatment and the tissue had to be kept unfixed. ${ }^{29}$ Therefore $\alpha, \alpha$-trehalase activity was used to classify the intestinal metaplasia, and type IIb could not be separated from type IIa, because the mucin staining technique requires fixation of the tissue. Although we could not differentiate between types IIa and IIb, no punched out lesion contained more than three glands of the same cell origin, excluding the possibility of monoclonal expansion of intestinal metaplasia.

We previously reported that about a half of the normal single fundic glands were heterotypic and almost all single pyloric glands were homotypic. ${ }^{28}$ The intestinal metaplastic gland is reported to arise by gradual change of a normal gland. ${ }^{3}$ In the present investigation, however, about half of the intestinal metaplastic glands were heterotypic even when they were in the antrum surrounded by pyloric glands that were homotypic. ${ }^{28}$ We can explain the existence of heterotypic and homotypic intestinal metaplastic glands among the fundic glands by the gradual change from normal glands, but a simple gradual change cannot explain the existence of heterotypic intestinal metaplastic glands among homotypic pyloric glands, if the original glands change to intestinal metaplastic type but retain the gland struc- 
ture, as X chromosome inactivation is reported not to change even in stem cells. ${ }^{23} 24$

We postulate two explanations for the occurrence of a heterotypic intestinal metaplastic gland in the antrum, which is originally covered by homotypic pyloric glands. ${ }^{28}$ One is that intestinal metaplastic tissue is formed through a process that incorporates a second stem cell, either from outside the normal gland or from outside of the cell regeneration system of a normal gland, namely a pluripotential dormant cell. In this mechanism, it is possible that the pre-existing normal pyloric gland is gradually replaced by intestinal-type cells. We know that a considerable proportion of intestinal metaplastic glands show both gastric and intestinal phenotypes. ${ }^{3}$ Therefore our present observation is consistent with previous ones. In addition, we know that even a normal intestinal crypt is formed as a polyclonal cell population in prenatal gut. ${ }^{34} \mathrm{Schmidt}$ et $a l^{35}$ reported that the intestinal crypts in chimeric mice are of polyclonal origin, and the differentiation of crypt cells occurs within two weeks of birth. It is possible that generation of intestinal metaplasia imitates ontogeny. ${ }^{2}$ This differentiation mechanism might explain the existence of both homotypic and heterotypic intestinal metaplastic glands. The intestinal metaplastic glands may arise polyclonally and may be "purified" into monoclonal populations. However, as we took all the punched out lesions from large, possibly fused, intestinal metaplastic areas in this experiment, we could not confirm this differentiation process with time.

There is another possible explanation. If we postulate that $\mathrm{X}$ chromosome inactivation is not determined in the stem cell of an intestinal metaplastic gland, a heterotypic gland may potentially arise from a single stem cell. The methylation of autosomal genes is known to be disturbed in the carcinogenesis process. $^{36}$ There might be a mechanism of methylation instability in the process of intestinal metaplasia. Our observations of three neighbouring glands showing RERs (fig 4) support this idea. Because RER is a rare event, it is unlikely to occur independently in three different neighbouring cells. Thus we assume that the three glands had originated from the same stem cell. However, we observed different methylation patterns among the glands.

We do not at present have any solid data to determine which of the above two theories is more likely. Somatic mutations, such as RERs in an intestinal metaplastic gland, may hold the key to the solution. Instability of $\mathrm{X}$ chromosome methylation, or possibly inactivation, may represent a new field of research on the differences in cancer susceptibility between men and women.

Sachiyo Nomura was awarded a Research Resident Fellowship from the Foundation for Promotion of Cancer Research. The
authors are grateful to Drs Y Hitomi and H Jimbo for their authors are grateful to Drs Y Hitomi and $\mathrm{H}$ Jimbo for their
critical discussions. This work was supported in part by a critical discussions. This work was supported in part by a Grant-in-Aid for Cancer Research for the second term compre-
hensive 10 year strategy for cancer control from the Ministry of hensive 10 year strat
Health and Welfare.

1 Slack JMW. Epithelial metaplasia and the second anatomy. Lancet 1986;2:268-71.

2 Slack JMW. Homeotic transformation in man: implications for the mechanism of embryonic development and for the organization of epithelia. $\mathcal{F}$ Theor Biol 1985;114:463-90.
3 Teir S, Rasanen T. A study of mitotic rate in renewal zones of nondiseased portions of gastric mucosa in cases of peptic ulcer and gastric cancer, with observations on differentiation and so-called "intestinalization" of gastric mucosa. $\mathcal{F}$ Natl Cancer Inst 1961;27:949-71.

4 Tateno I, Oohara T, Kondo Y. Morphological study of genesis and development of gastric intestinal metaplasia. fpn $\mathcal{f}$ Surg 1987;88:283-93.

5 Morson BC. Carcinoma arising from areas of intestinal metaplasia in the gastric mucosa. Br f Cancer 1955;9:377-85.

6 Stemmermann GN. Intestinal metaplasia of the stomach. Cancer 1994;74:556-64.

7 Jass JR. Role of intestinal metaplasia in the histogenesis of gastric carcinoma. F Clin Pathol 1980;33:801-10.

8 Sipponen P, Seppala K, Varis K, et al. Intestinal metaplasia with colonic-type sulphomucins in the gastric mucosa; its association with gastric carcinoma. Acta Pathol Microbiol Scand Sect A 1980;88:217-24.

9 Filipe MI, Potet F, Bogomoletz WV, et al. Incomplete sulphomucin-secreting intestinal metaplasia for gastric cancer. Preliminary data from a prospective study from three centers. Gut 1985;26:1319-26.

10 Filipe MI, Munoz N, Matko I, et al. Intestinal metaplasia types and the risk of gastric cancer: a cohort study in Slovenia. Int $\mathcal{F}$ Cancer 1994;57:324-9.

11 Kawachi T, Kurisu M, Numanyu N, et al. Precancerous changes in the stomach. Cancer Res 1976;36:2673-7.

12 Mullen PJ, Carr N, Milton JD, et al. Immunohistochemical detection of $\mathrm{O}$-acetylated sialomucins in intestinal metaplasia and carcinoma of the stomach. Histopathology 1955; 27:161-7.

13 Matsukura N, Suzuki K, Kawachi T, et al. Distribution of marker enzymes and mucin in intestinal metaplasia in human stomach and relation of complete and incomplete types of intestinal metaplasia to minute gastric cancer. $\mathfrak{F}$ Natl Cancer Inst 1980;65:231-40.

14 Kern SE. Clonality: more than just a tumor-progression model. I Natl Cancer Inst. 1993;85:1020-1.

15 Fialkow PJ. Clonal origin of human tumors. Biochim Biophys Acta 1976;458:283-321.

16 Wainscoat J, Fey M. Assessment of clonality in human tumors: a review. Cancer Res 1990;50;1355-60.

17 Williams G, Wynford-Thomas D. How may clonality be assessed in human tumors? Histopathology 1994;24;287-92.

18 Noguchi S, Motomura $\mathrm{K}$, Inaji $\mathrm{H}$, et al. Clonal analysis of parathyroid adenomas by means of the polymerase chain parathyroid adenomas by means of

19 Herman V, Fagin J, Gonsky R, et al. Clonal origin of pituitary adenomas. F Clin Endocrinol Metab 1990;71:1427-33. 20 Fearon ER, Hamilton SR, Vogelstein B. Clonal analysis of human colorectal tumors. Science 1987;238:193-7.

21 Novelli MR, Williamson JA, Tomlinson IPM, et al. Polyclonal origin of colonic adenomas in an XO/XY patient with FAP. Science 1996;272:1187-90.

22 Vogelstein B, Fearon ER, Hamilton SR, et al. Use of restriction fragment length polymorphism to determine the clonal origin of human tumors. Science 1985;227:642-5.

23 Lyon MF. Gene action in the X-chromosome of the mouse (Mus musculus L). Nature 1961;190:372-3.

24 Lyon MF. X-chromosome inactivation and the location and expression of X-linked genes. Am f Hum Genet 1988;42:816.

25 Allen RC, Zoghbi HY, Mosely AB, et al. Methylation of $H p a I I$ and $H h a$ I sites near the polymorphic CAG repeat in the human androgen-receptor gene correlates with $\mathrm{X}$ chromosome inactivation. Am f Hum Genet 1992;51:1229-39.

26 Mutter G, Boynton K. PCR bias in amplification of androgen receptor alleles, a trinucleotide repeat marker used in clonality studies. Nucleic Acid Res 1995;23:1411-18.

27 Sugimura T, Kawachi T, Kogure K. A novel method for detecting intestinal metaplasia of the stomach with Tes-Tape. Gann 1971;62:237-8.

28 Nomura S, Kaminishi M, Sugiyama K, et al. Clonal analysis of isolated single fundic gland and pyloric gland of stomach using X-linked polymorphism. Biochem Biophys Res Commun 1996;226:385-90.

29 Cheng H, Bjerknes M, Amar J. Methods for the determination of epithelial cell kinetic parameters of human colonic epithelium isolated from surgical and biopsy specimens. Gastroenterology 1984;86:78-85.

30 Irvine RA, Yu MC, Ross RK, et al. The CAG and GGC microsatellites of the androgen receptor gene are in linkage disequilibrium in men with prostate cancer. Cancer Res 1995;55:1937-40.

31 Ponder BAJ, Schmidt GH, Wilkinson MM, et al. Derivation of mouse intestinal crypts from single progenitor cells. Nature 1985;313:689-91.

32 Tsai YC, Lu Y, Nichols PW, et al. Contiguous patches of normal human mammary epithelium derived from a single stem cell: implications for breast carcinogenesis. Cancer Res 1996;56:402-4

33 Bjerknes M, Cheng H, Kim H, et al. Clonality of dysplastic epithelium in colorectal adenomas from familial adenomatous polyposis patients. Cancer Res 1997;57:355-61.

34 Ochiai A, Yamaguchi Y, Hirohashi S. p53 mutations in the non-neoplastic mucosa of the human stomach showing intestinal metaplasia. Int f Cancer 1996;69:28-33.

35 Schmidt GH, Winton DJ, Ponder BAJ. Development of the pattern of cell renewal in the crypt-villus unit of chimaeric pattern of cell renewal in the crypt-villus unit of chima

36 Jones PA. DNA methylation errors and cancer. Cancer Res 1996;56:2463-7. 